Portland State University

PDXScholar

Environmental Science and Management

Faculty Publications and Presentations

\title{
The Interactive Effect of Multiple Stressors on Crustacean Zooplankton Communities in Montane Lakes
}

Jeffrey Thomas Brittain

Portland State University, jtbrittain@gmail.com

Angela L. Strecker

Portland State University, angela.strecker@wwu.edu

Follow this and additional works at: https://pdxscholar.library.pdx.edu/esm_fac

Part of the Environmental Indicators and Impact Assessment Commons, and the Natural Resources Management and Policy Commons

Let us know how access to this document benefits you.

\section{Citation Details}

Brittain, J.T. and A.L. Strecker. 2018. The interactive effect of multiple stressors on crustacean zooplankton communities in montane lakes. Water Resources Research; Vol 58, Issue 2.

This Article is brought to you for free and open access. It has been accepted for inclusion in Environmental Science and Management Faculty Publications and Presentations by an authorized administrator of PDXScholar. Please contact us if we can make this document more accessible: pdxscholar@pdx.edu. 


\section{Water Resources Research}

\section{RESEARCH ARTICLE \\ 10.1002/2017WR020605 \\ The Interactive Effect of Multiple Stressors on Crustacean Zooplankton Communities in Montane Lakes}

Special Section:

Responses to Environmental Change in Aquatic Mountain Ecosystems

Key Points:

- Montane lakes can be used as early indicators of the impacts of environmental stressors on aquatic communities at lower elevations - Zooplankton from a fishless and fish-present lake were subjected to acidification and nutrient enrichment from nitrogen deposition

- Zooplankton responded differently to nitrogen by lake type and the combination of acid and nitrogen resulted in ecological surprises

Supporting Information: - Supporting Information S1

Correspondence to:

J. T. Brittain,

jtbrittain@gmail.com

\section{Citation:}

Brittain, J. T., \& Strecker, A. L. (2018). The interactive effect of multiple stressors on crustacean zooplankton communities in Montane Lakes. Water Resources Research, 54, 939-954. https://doi.org/10.1002/ 2017WR020605

Received 23 FEB 2017 Accepted 16 JAN 2018 Accepted article online 18 JAN 2018 Published online 9 FEB 2018

(c) 2018. American Geophysical Union. All Rights Reserved.

\author{
Jeffrey T. Brittain ${ }^{1}$ (D) and Angela L. Strecker ${ }^{1}$ \\ ${ }^{1}$ Environmental Science \& Management, Portland State University, Portland, OR, USA
}

\begin{abstract}
Nonnative fish introductions have altered thousands of naturally fishless montane lakes, resulting in cascading food web repercussions. Nitrogen deposition has been recognized as an anthropogenic contributor to acidification and eutrophication of freshwater ecosystems, which may affect the abundance and composition of planktonic communities. This study identified responses of zooplankton communities from two lakes (fish present versus absent) in Mount Rainier National Park to manipulations simulating an episodic disturbance of acidification and eutrophication via nitrogen addition in mesocosms. Zooplankton communities from lakes with different food web structure (i.e., fish present or absent) responded differently to the singular effects of acid and nitrogen addition. For instance, zooplankton biomass decreased in the acid treatment of the fishless lake experiment, but increased in response to acid in the fish-present experiment. In contrast, the combination of acid and nitrogen often resulted in weak responses for both lake types, resulting in nonadditive effects, i.e., the net effect of the stressors was in the opposite direction than predicted, which is known as a reversal or "ecological surprise." This experiment demonstrates the difficulty in predicting the interactive effects of multiple stressors on aquatic communities, which may pose significant challenges for habitat restoration through fish removal.
\end{abstract}

\section{Introduction}

The remote montane lakes found in high elevation regions have been referred to as sentinels of change for their use in monitoring shifting climate regimes and levels of anthropogenic influence across the landscape (Battarbee et al., 2009; Williamson et al., 2008). Although these high elevation lakes are often regarded by the public as pristine ecosystems, many have experienced extensive disturbance, such as nonnative species introductions (Eby et al., 2006), atmospheric pollution (Baron et al., 2000), climate change (Battarbee et al., 2002), and an increased susceptibility to UV radiation (Schindler et al.,1996).

The stocking of nonnative fishes into mountain lakes is a common practice globally (Pister, 2001; Schindler \& Parker, 2002). Nonnative fishes can significantly alter food web structure by assuming the position of top predator (Vander Zanden et al., 1999). For instance, trout stocking has resulted in declines of amphibians, macroinvertebrates, and plankton communities in lakes that were historically fishless (Knapp et al., 2001; Pilliod \& Peterson, 2001; Schilling et al., 2009). One of the most significant effects of introducing planktivorous fishes is size-selective predation of large-bodied zooplankton, like Daphnia (Brooks \& Dodson, 1965). In lakes where fish populations are abundant, less efficient small-bodied grazers will dominate the zooplankton community as a result of size-selective predation (Hall et al., 1976) and primary productivity is expected to increase. In lakes where fish are absent, a higher abundance of large-bodied zooplankton is expected (Liss et al., 2002).

An additional stressor in mountain lakes is the deposition of atmospheric nitrogen $(\mathrm{N})$, which has been linked to elevated lake nitrate concentrations and shifts in phytoplankton communities (Baron et al., 2000). Nitrogen deposition can impact aquatic systems by increasing the amount of reactive nitrogen, which could result in both acidification and eutrophication (Galloway et al., 2003). Mountain lakes are particularly susceptible to the effects of acidification because of poor buffering capacity (Armstrong \& Schindler, 1971; Brakke \& Loranger, 1987; Clow et al., 2002). Acidification can alter zooplankton communities through reductions in abundance, biomass, diversity, and a loss of acid-sensitive species (i.e., herbivores, large-bodied species) (Confer et al., 1983; Havens et al., 1993; Keller \& Yan, 1998; McCullough \& Horwitz, 2010). Phytoplankton biomass may increase in acidified lakes as a result of increases in large inedible phytoplankton that zooplankton cannot readily consume (Schindler, 1990). 
In temperate lakes, nutrient additions can lead to enhanced growth rates of phytoplankton production, as well as nuisance and harmful algal blooms (Anderson et al., 2002). However, in ultraoligotrophic lakes it is possible that slight nitrogen increases may not lead to degradation, but rather enrich the system by providing a limiting nutrient, after which further perturbation pushes the system beyond its normal operating range, leading to stress effects (Odum et al., 1979). Williams et al. (2016) observed increased phytoplankton biomass in response to elevated nitrogen concentrations in bioassays from oligotrophic mountain lakes. However, the effects of increased nutrients on zooplankton are equivocal. In oligotrophic systems, bottomup control is most important, where phytoplankton are limited by nutrient availability, which limits zooplankton, and can result in positive correlations between zooplankton and phytoplankton (McQueen et al., 1986). However, top-down regulation of phytoplankton by zooplankton may also result in a negative relationship, particularly if Daphnia (a keystone species) is present (McQueen et al., 1986). Mesocosm experiments suggest that nutrients can have a positive effect on zooplankton biomass in shallow eutrophic lakes with fish removed (Vakkilainen et al., 2004) and in fishless oligotrophic lakes (Neill, 1984), but this effect could be mediated by the presence of planktivorous fish.

Multiple stressors are common in natural systems, yet it is difficult to predict whether their interaction will exacerbate or ameliorate the effects of individual stressors on communities (Folt et al., 1999). A recent review of multiple stressors in freshwater ecosystems showed that the combined effects of stressors most often elicited an antagonistic response, indicating that the combined effects of stressors were less than the sum of the stressors independent effects (Jackson et al., 2016). In mountain lakes, the preexisting condition of the ecosystem largely determines whether acidification or eutrophication will occur first; however both stressors can result in a loss of phytoplankton diversity (Baron et al., 2011) and shifts in phytoplankton species composition (Lafrancois et al., 2004). However, no studies have explored how these stressors impact plankton communities based on differences in food web structure that result from historical fish stocking.

Our objective was to identify the response of zooplankton communities in montane lakes of differing fish stocking histories to acidification and eutrophication manipulations. In the western United States, 95\% of $>16,000$ historically fishless lakes were stocked with fish (Bahls, 1992). Research on the ecological effects of nitrogen deposition has occurred in the U.S. Rocky Mountains and Sierra Nevada; however, little is known about the effects of $\mathrm{N}$ deposition in other regions (Fenn et al., 2003; Nanus \& Clow, 2004). The Cascade Mountains of Oregon and Washington contain a relatively high percentage of lakes believed to be $\mathrm{N}$ limited, thus making them susceptible to chemical and biological changes from nitrogen deposition (Baron et al., 2011; Elser et al., 2009).

We conducted two simultaneous mesocosm experiments to assess the singular and interactive effects of acid and nitrogen, one using plankton communities from a fish-present lake and another using plankton from a fishless lake (Figure 1). We tested three main hypotheses. First, we expected that acidification would decrease zooplankton abundance, with greater effects on communities from fishless lakes. These communities may be less resilient due to a greater abundance of acid-sensitive taxa, i.e., large-bodied crustaceans (Havens et al., 1993). Second, we predicted that the nitrogen treatment would increase phytoplankton (e.g., Williams et al., 2016), but the presence of larger-bodied zooplankton in the fishless community would more effectively control phytoplankton growth (Sarnelle \& Knapp, 2005) compared to the less efficient grazers in the fish-present zooplankton community. This should lead to an increase in zooplankton abundance in the fishless community. Third, we hypothesized that the positive effects of nitrogen would buffer the negative effects of acid, such that there would be minor or no change in zooplankton communities in the nitrogen + acid treatment. Using systems with these legacies can help to identify the interactive effects of multiple stressors, allowing for projections of how lakes in more temperate climates could respond in the future.

\section{Methods}

\subsection{Study Site and Experimental Setup}

The experiment was conducted in Mount Rainier National Park at the park headquarters in Longmire, WA, USA. Minimal disturbance to native flora and fauna was achieved by placing the main tank array outside of the designated wilderness area, and using a common garden experimental design to source water from a single site, Mowich Lake, which has similar physical and chemical characteristics to other study lakes, discussed below (Table 1). A common garden design is ideal for this type of study because both communities 

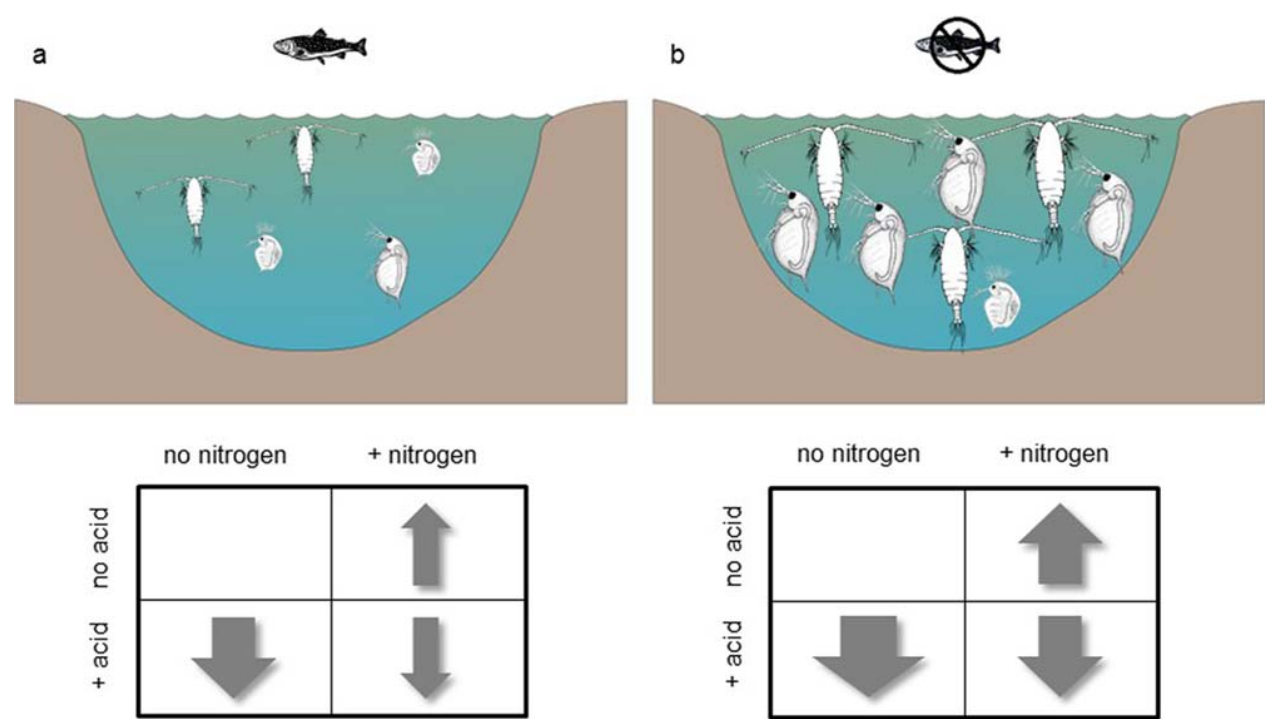

Figure 1. Conceptual diagram of experimental design, where the (a) fish-present lake is characterized by smaller zooplankton in low abundances, in contrast to the (b) fishless lake, which is characterized by larger zooplankton in greater abundances. Directional arrows indicate predicted changes to zooplankton abundance resulting from acidification and nitrogen addition based on fish presence or absence, while width indicates magnitude of change. We hypothesized that the acid treatment would have the most negative effects on zooplankton, but that the positive effects of the nitrogen treatment would moderate the effects of the acid in the nitrogen + acid treatment combination. We propose that the magnitude of effects will be greatest in the fishless lake because of the dominance of acid-sensitive large-bodied taxa.

were subjected to the same conditions, allowing for changes to be attributed to the treatments. Mowich Lake is the deepest lake in the park, and park officials determined water withdrawal from Mowich posed the smallest disturbance compared to the smaller study lakes. Like many lakes in the Cascades, these sites are oligotrophic and remain frozen over for up to 8 months of the year.

A $2 \times 2$ factorial design was used to allow two treatments (acid and nitrogen) to be studied at two levels (with and without addition). Each treatment combination was replicated four times. The experiment was replicated using plankton from a fishless lake (Clover Lake) and from a fish-present lake (Snow Lake), such that the two factorial experiments were run simultaneously. Zooplankton were collected from Snow Lake and Clover Lake, which were both historically fishless waterbodies, but were subjected to a legacy of fish stocking. The park began recording stocking data for both lakes in 1926, which included introductions of steelhead and rainbow trout (Oncorhynchus mykiss), cutthroat trout (Oncorhynchus clarkii), and brook trout (Salvelinus fontinalis) until 1962 (Clover Lake) and 1970 (Snow Lake). Snow Lake continues to support

Table 1

Physicochemical Conditions of Study Lakes

\begin{tabular}{lccc}
\hline Variable & $\begin{array}{c}\text { Mowich Lake } \\
\text { (water source) }\end{array}$ & $\begin{array}{c}\text { Snow Lake } \\
\text { (fish-present experiment) }\end{array}$ & $\begin{array}{c}\text { Clover Lake } \\
\text { (fishless experiment) }\end{array}$ \\
\hline Latitude $(\mathrm{N})$ & $46^{\circ} 56^{\prime} 16.08^{\prime \prime}$ & $46^{\circ} 45^{\prime} 27.85^{\prime \prime}$ & $46^{\circ} 55^{\prime} 44.75^{\prime \prime}$ \\
Longitude $(\mathrm{W})$ & $121^{\circ} 51^{\prime} 44.75^{\prime \prime}$ & $121^{\circ} 41^{\prime} 52.96^{\prime \prime}$ & $121^{\circ} 35^{\prime} 36.41^{\prime \prime}$ \\
Elevation $(\mathrm{m})$ & 1,500 & 1,424 & 1,743 \\
Maximum depth $(\mathrm{m})$ & 60.0 & 10.9 & 14.0 \\
Area $($ ha) & 45.0 & 2.6 & 2.5 \\
pH & $7.02^{\mathrm{a}}$ & $6.90^{\mathrm{a}}$ & $6.90^{\mathrm{a}}$ \\
Specific conductance $\left(\mu \mathrm{S} \cdot \mathrm{cm}^{-1}\right)$ & $12.5^{\mathrm{a}}$ & $10.8^{\mathrm{a}}$ & $14.0^{\mathrm{a}}$ \\
Secchi depth $(\mathrm{m})$ & $19.0^{\mathrm{a}}$ & $7.0^{\mathrm{a}}$ & $12.0^{\mathrm{a}}$ \\
Total phosphorus $\left(\mu \mathrm{g} \cdot \mathrm{L}^{-1}\right)$ & $3.3^{\mathrm{b}}$ & $4.8^{\mathrm{b}}$ & $4.1^{\mathrm{b}}$ \\
Total nitrogen $\left(\mu \mathrm{g} \cdot \mathrm{L}^{-1}\right)$ & $35.0^{\mathrm{b}}$ & $20.0^{\mathrm{b}}$ & $53.8^{\mathrm{b}}$ \\
\hline
\end{tabular}

a Values averaged across study period, and collected from surface water where applicable. ${ }^{\text {b Unpublished seasonally }}$ averaged surface water data from Robert Hoffman (U.S. Geological Survey, Corvallis, Oregon). 
populations of fish, while the absence of fish in Clover Lake was confirmed by snorkel surveys in 2013. Though these fish species are not typically known as planktivores, there are multiple lines of evidence that they readily consume zooplankton in these resource-limited mountain systems (Eby et al., 2006 and references therein). For instance, a study from Utah found that both brook trout and cutthroat trout consume diaptomid copepods, Daphnia, and other crustacean zooplankton in mountain lakes (Carlisle \& Hawkins, 1998). Recent surveys (1999-2015) have indicated that the fish present in Snow Lake are small: brook trout averaged $210 \mathrm{~mm}$ (range 179-239 mm), while cutthroat trout averaged $217 \mathrm{~mm}$ (range 193-241 mm), which suggests that zooplanktivory is likely (e.g., Tremblay \& Magnan, 1991).

The body size, composition, and density of zooplankton in our study lakes was largely reflective of other fishless and fish-present mountain lakes in the region and beyond (e.g., Donald et al., 2001). Most strikingly, zooplankton densities in our fishless lake were more than 2 orders of magnitude larger than the fish-present lake, with densities averaging $\sim 7,605$ individuals $\cdot \mathrm{m}^{-3}$ compared to $\sim 73$ individuals $\cdot \mathrm{m}^{-3}$, respectively. At the beginning of the experiment, the fish-present lake was dominated by two copepods: Hesperodiaptomus franciscanus (70\%) and Eucyclops agilis (29\%), with no Daphnia or Holopedium present (supporting information S1, Figure S1-1). This trend continued throughout the summer, with cladocerans comprising, on average, $\sim 2 \%$ of the community. Copepods are generally thought to be better than cladocerans at avoiding predation by fish (Hambright \& Hall, 1992). By contrast, the fishless lake was comprised of Hesperodiaptomus franciscanus (69\%), Holopedium gibberum (18\%), and Daphnia pulicaria (13\%) at the start of the experiment, but switched to codominance by Daphnia later in the summer (supporting information S1, Figure S1-1). In addition, the average body size of zooplankton in the fishless lake was $\sim 200 \mu \mathrm{m}$ larger than zooplankton in the fishpresent lake at the start of the experiment (fishless: $948 \mu \mathrm{m}$; fish-present: $768 \mu \mathrm{m}$ ). It is possible that differences in zooplankton abundance or biomass, body size, and community composition could be the result of factors other than fish, such as water chemistry, lake morphometry, productivity, and water temperature (e.g., Messner et al., 2013; Strecker et al., 2008). Water chemistry, including pH and specific conductance, and lake morphometry variables were similar across study lakes (Table 1). Conversely, total phosphorus and Secchi depth suggest that Snow Lake (fish) is likely more productive than fishless Clover Lake (Table 1), which should lead to larger and more abundant zooplankton; however, this is the opposite of what we observed (supporting information S1, Figure S1-1). Water temperature is another factor that can affect zooplankton: fishless Clover Lake is warmer than fish-present Snow Lake (supporting information S1, Figure S12), which could have affected zooplankton abundance. However, survey data from mountain lakes indicate that warmer fishless lakes have lower zooplankton biomass than colder fish-present lakes (Messner et al., 2013). Additionally, warmer water temperatures have experimentally been shown to decrease zooplankton biomass in alpine lakes (Strecker et al., 2004). Thus, our data do not support these alternative hypotheses and the presence of fish seems to be the most parsimonious explanation for differences in zooplankton communities.

Thirty-two $140 \mathrm{~L}$ gray Rubbermaid polyethylene tanks were used to simulate ambient lake conditions. Tanks were filled with water from the epilimnion of Mowich Lake, which was filtered through $80 \mu \mathrm{m}$ mesh to remove Mowich Lake zooplankton. Zooplankton were collected mid-afternoon at the deepest spot of the fish-present and fishless lakes, from $2 \mathrm{~m}$ above the lake bottom to the surface (accounting for the length of the net) using a $30 \mathrm{~cm}$ diameter plankton net with $80 \mu \mathrm{m}$ mesh. Zooplankton were stored in $19 \mathrm{~L}$ carboy containers, and transported to the experimental tanks, where they were added to tanks at $1.5 \mathrm{X}$ ambient density from each source lake. Aquatic predators, such as mosquito larvae, were removed by hand. Tanks were inoculated with zooplankton from the fish-present lake (Snow) and the fishless lake (Clover) on 14 August and 15 August 2013, respectively. Tanks were located in partial shade and covered with mesh to prevent aerial colonization.

In order to ensure that the source water did not have an undue influence on zooplankton communities in the experiment, we established reference mesocosms using water from either the fishless lake or fishpresent lake (i.e., Clover zooplankton in Clover water, Snow zooplankton in Snow water). These reference mesocosms were situated at the lakes in order to obtain water for the experiments, in contrast to the main experimental mesocosms, which were located at the park headquarters. Despite some early initial differences, zooplankton abundance was not significantly greater in reference tanks (using Clover or Snow Lake water) compared to control tanks (using Mowich Lake water) over the course of the experiment (supporting 
information S1, Figure S1-2, Table S1-1), indicating that source water had no significant influence on the experiment. These early differences are likely due to zooplankton acclimation and stress from transport.

Treatments of nitrogen and acid (as $\mathrm{KNO}_{3}$ and $\mathrm{HCl}$, respectively) were added on 17 August 2013 to randomly assigned tanks, simulating a single episodic pulse characteristic of a spring melt event. Tanks with nitrogen addition received $69.3 \mu \mathrm{g} \cdot \mathrm{L}^{-1}$ of nitrogen as $\mathrm{KNO}_{3}$ to mimic a $30-40 \%$ increase above ambient levels, representing potential nitrogen concentrations resulting from spring glacial melt as observed in other mountainous areas of the West (Baron et al., 2011; Clow \& Campbell, 2008; Nanus et al., 2012). Though this nitrogen addition is modest, it is within the range of concentrations observed to promote increases in phytoplankton in mountain lakes (Williams et al., 2016). Tanks with acid addition were titrated from a pH $\sim 7$ to an endpoint of $\mathrm{pH} 5.5$ to mimic moderate acidification, which has been used in similar studies to identify impacts related to atmospheric deposition (Lafrancois et al., 2004). Large-bodied adult crustaceans begin to decline at $\mathrm{pH}<6.0$ (Havens et al., 1993), thus our treatment is reasonable.

\subsection{Sampling and Sample Processing}

Sampling of experimental tanks took place weekly, from 16 August 2013 (week 1, pretreatment baselines) to 20 September 2013 (week 6). The lakes were also sampled each week to compare differences in environmental conditions and plankton composition to the tanks. Water temperature, dissolved oxygen, and specific conductance were measured from mid-depth in the tanks and in the lakes at surface and $1 \mathrm{~m}$ intervals using a YSI ProPlus (Yellow Springs, $\mathrm{OH}$ ) at midday. Water temperature was consistent between treatments over time; on average, temperature varied less than $0.30^{\circ} \mathrm{C}$ between all tanks (supporting information S1, Table S2-1, Figure S2-1). Water temperature of the mesocosms was usually warmer than the lake surface temperature for the fish-present lake (mesocosm average $=14.8^{\circ} \mathrm{C} \pm 1.9 \mathrm{SD}$; lake average $=12.1^{\circ} \mathrm{C} \pm 1.3$ $\mathrm{SD}$ ), but roughly the same in the fishless lake (mesocosm average $=14.8^{\circ} \mathrm{C} \pm 1.9 \mathrm{SD}$; lake average $=16.1^{\circ} \mathrm{C}$ $\pm 1.1 \mathrm{SD}$ ). Dissolved oxygen ( $\mathrm{mg} \cdot \mathrm{L}^{-1}$ ) was not significantly different between tanks throughout the experiment for either community (supporting information S1, Table S2-1, Figure S2-1), though the mesocosms had lower dissolved oxygen (\% saturation) than the lakes, likely due to reduced mixing (fish-present averages: mesocosms $=71.1 \% \pm 5.9$ SD; lake $=93.6 \% \pm 8.2$ SD; fishless averages: mesocosms $=72.2 \% \pm 4.8$ SD; lake $=87.0 \% \pm 6.7 \mathrm{SD}$ ). The $\mathrm{pH}$ of surface water was measured in situ using an Orion $290 \mathrm{~A} \mathrm{pH}$ meter (Thermo Fisher Scientific, Waltham, MA). Specific conductance and $\mathrm{pH}$ of the mesocosms was similar to the lake, though specific conductance in the fish-present lake was lower than the mesocosms, reflecting the different source water origin (Table 1 ; mesocosm average $=17.0 \mu \mathrm{s} \cdot \mathrm{cm}^{-1} \pm 2.6 \mathrm{SD}$; lake average $=10.7$ $\left.\mu \mathrm{s} \cdot \mathrm{cm}^{-1} \pm 0.4 \mathrm{SD}\right)$.

Water for nutrient analysis was collected from the epilimnion using a $10 \mathrm{~m}$ long, $2.54 \mathrm{~cm}$ diameter tygon tube, and from the tanks with grab samples once they had been mixed. Water was transferred into $125 \mathrm{~mL}$ HDPE bottles and kept cool until frozen in the laboratory. Total phosphorus (TP) samples were digested with a persulfate solution and heat, and analyzed on a Shimadzu UV-1800 Spectrophotometer (Shimadzu, Kyoto, Japan) using the molybdenum blue colorimetric method (method detection limit: $0.002 \mathrm{mg} \cdot \mathrm{L}^{-1}$; precision: $\pm 0.004 \mathrm{mg} \cdot \mathrm{L}^{-1}$ ) (Cooperative Chemical Analytical Laboratory, 2010). In order to test whether the nitrogen addition was effective, a subset of tanks that received nitrogen $(n=8)$ were randomly chosen and sampled after the treatment application on week 2, in addition to analyses of all tanks on week 6 . Total nitrogen samples (TN) were digested with a persulfate solution and analyzed on a Technicon Auto-Analyzer II (Seal Analytical, Mequon, Wisconsin) with a colorimetric determination of nitrate and nitrite (method detection limit: $0.01 \mathrm{mg} \cdot \mathrm{L}^{-1}$; precision: $\pm 0.01 \mathrm{mg} \cdot \mathrm{L}^{-1}$ ) (Cooperative Chemical Analytical Laboratory, 2013).

Water for chlorophyll $a$ analysis was collected from the epilimnion using the aforementioned tygon tube, and from the tanks with grab samples once they had been mixed. Water for chlorophyll analysis was divided into two fractions, one passing through a $35 \mu \mathrm{m}$ filter to represent the highly edible algal fraction (Cyr \& Curtis, 1999), and one unfiltered to represent total algae, using chlorophyll $a$ as a proxy of algal biomass. Though zooplankton can consume larger size fractions of phytoplankton, we believe that $35 \mu \mathrm{m}$ represents a realistic benchmark of highly edible taxa. Each fraction was filtered onto a $1.2 \mu \mathrm{m}$ pore size glass fiber filter and frozen. Periphyton was collected on two porcelain tiles, which were placed in the tanks on week 1, individually scraped at two intervals (weeks 3 and 6), and filtered through a glass fiber filter. Chlorophyll $a$ was extracted with acetone for $20 \mathrm{~h}$ in a dark refrigerator, and concentrations were measured on a 
TD-7200 fluorometer (Turner Designs, Sunnyvale, CA), using the modified fluorometric technique (Arar \& Collins, 1997).

Zooplankton were sampled from each tank by mixing the water and collecting from the bottom to the top of the tank using a $2.5 \mathrm{~L}$ bucket, and poured through an $80 \mu \mathrm{m}$ mesh filter. Six replicate hauls, representing a total filtered volume of $10 \%$ of the tank volume, were collected. Weekly samples were taken from each lake using identical methods to those described above for the experimental setup. Zooplankton were preserved in a $70 \%$ ethanol solution. Taxonomic guides were used to identify adult crustacean taxa (Haney, 2013; Thorp \& Covich, 2009) to species level when possible using a Leica M165C microscope and IC80HD camera (Leica Microsystems Inc., Buffalo Grove, IL), following EPA protocol (Environmental Protection Agency, 2003). Zooplankton abundance was calculated by counting the entire sample, which ranged from 0 to 459 individuals (mean $=71.2 \pm 86.6$ SD). Biomass was estimated by measuring the length of a subset of 10 animals per taxa in each sample, which were averaged to calculate biomass with length-weight regressions (Culver et al., 1985; Lawrence et al., 1987; McCauley, 1984). Zooplankton body size was calculated based on length measurements, using abundance-weighted averages in each treatment.

\subsection{Statistical Analyses}

Two-factor analysis of variance (ANOVA), two-factor repeated measures ANOVA (RM-ANOVA), and a permutational multivariate analysis of variance (MANOVA) were used to test the singular and interactive impacts of eutrophication and acidification using $\mathrm{R}$ version 3.0.1 (R Core Team, 2013) with the $E Z$ and vegan libraries (Lawrence, 2013). Environmental conditions (temperature, dissolved oxygen, specific conductance, $\mathrm{pH}$, and total phosphorus), total chlorophyll $a$, and edible chlorophyll $a$ were compared between treatments using a RM-ANOVA performed separately on the two lake types (fish-present and fishless lakes) for weeks 2-6 (excluding week prior to treatments being added). A two-way ANOVA was used on total nitrogen for week 6. Periphyton growth as measured in chlorophyll $a$ was tested with a two-factor RM-ANOVA on samples for weeks 4 and 6 . Variables with statistically significant interactions were visually inspected using interaction plots. The response of zooplankton community composition to treatments for weeks 2-6 was tested using a permutational MANOVA ( $n=9,999$ permutations) (Anderson, 2001). Species abundances were Hellinger transformed prior to testing (Legendre \& Gallagher, 2001).

The assumptions of normality, homogeneity, and sphericity were tested using the Shapiro-Wilk, Levene's, and Mauchly's tests, respectively. Violations of sphericity used Greenhouse-Geisser corrections. Environmental conditions and zooplankton community data between treatments were compared on week 1 (prior to treatment additions) with a two-factor ANOVA and determined that there were no significant differences prior to treatment application, with the exception of body size in the nitrogen treatment of the fishless experiment (supporting information S1, Table S2-2). However, this difference is likely not biologically relevant, as the difference in body size was $<100 \mu \mathrm{m}$ (control: $1162 \mu \mathrm{m} \pm 230$ SD; nitrogen: $1248 \mu \mathrm{m} \pm 92$ SD). Last, in order to evaluate the combined effect of stressors, we calculated the predicted additive effect $\left(X_{p}\right)$ of zooplankton community metrics following Jackson et al. (2016):

$$
X_{p}=\left(X_{n}-X_{u}\right)+\left(X_{a}-X_{u}\right)+X_{u}
$$

where $X_{u}$ is the control, $X_{n}$ is the nitrogen treatment, and $X_{a}$ is the acid treatment.

\section{Results}

\subsection{Environmental Conditions}

The treatment applications in the tanks created the desired conditions and suggest that these simulations were responsible for impacting the plankton communities rather than the minor differences that existed in other environmental variables (e.g., temperature). As expected, $\mathrm{pH}$ was significantly reduced in the acid treatment for both sets of experiments: $\mathrm{pH}$ decreased by $17 \%$ (average 6.0 in acid treatments versus 6.6 in nonacid treatments) and 16\% (average 5.9 in acid treatments versus 6.6 in nonacid treatments) in the fishpresent and fishless experiment, respectively (supporting information S1, Table S2-1, Figure S2-1). Total nitrogen was significantly higher (33\%) in the tanks with nitrogen addition (average $280 \mu \mathrm{g} \cdot \mathrm{L}^{-1}$ ) compared to tanks without nitrogen addition on week 2 (average $210 \mu \mathrm{g} \cdot \mathrm{L}^{-1}$ ), indicating that the nitrogen addition was successful (supporting information S1, Table S2-3, Figure S2-2). Total nitrogen was not observed to be significantly different between treatments on week 6 (supporting information S1, Figure S2-2), which was 
Table 2

Statistical Summary of RM-ANOVA on Total and Edible Chlorophyll a Fractions for Weeks 2-6, While Periphyton Statistics Are for Weeks 4 \& 6

\begin{tabular}{|c|c|c|c|c|c|c|c|}
\hline \multirow[b]{2}{*}{ Variable } & \multirow[b]{2}{*}{ Treatment } & \multicolumn{3}{|c|}{ Fish-present experiment } & \multicolumn{3}{|c|}{ Fishless experiment } \\
\hline & & F-ratio & $p$-value & ES & F-ratio & $p$-value & ES \\
\hline \multirow{7}{*}{$\begin{array}{l}\text { Total } \\
\text { chlorophyll } a\end{array}$} & Nitrogen $[1,12]$ & 6.496 & $0.026^{* *}$ & $\uparrow 126 \%$ & 1.492 & 0.245 & \\
\hline & Acid $[1,12]$ & 0.001 & 0.971 & & 2.587 & 0.134 & \\
\hline & Nitrogen $\times$ Acid $[1,12]$ & 0.144 & 0.711 & & 3.483 & $0.087^{*}$ & $\uparrow 48 \%$ \\
\hline & Time $[4,48]$ & 3.098 & $0.024^{* *}$ & & 0.778 & 0.545 & \\
\hline & Time $\times$ Nitrogen $[4,48]$ & 0.332 & 0.855 & & 0.417 & 0.795 & \\
\hline & Time $\times$ Acid $[4,48]$ & 0.442 & 0.777 & & 0.222 & 0.925 & \\
\hline & Time $\times$ Nitrogen $\times$ Acid $[4,48]$ & 0.247 & 0.910 & & 0.814 & 0.522 & \\
\hline \multirow{7}{*}{$\begin{array}{l}\text { Edible } \\
\text { chlorophyll } a\end{array}$} & Nitrogen $[1,12]$ & 9.790 & $0.009^{* *}$ & $\uparrow 135 \%$ & 3.489 & $0.086^{*}$ & $\downarrow 52 \%$ \\
\hline & Acid $[1,12]$ & 2.870 & 0.116 & & 1.156 & 0.303 & \\
\hline & Nitrogen $\times$ Acid $[1,12]$ & 5.485 & $0.037^{* *}$ & $\uparrow 203 \%$ & 4.64 & $0.052^{*}$ & $\downarrow 46 \%$ \\
\hline & Time $[4,48]$ & 4.828 & $0.002^{* *}$ & & 1.069 & 0.382 & \\
\hline & Time $\times$ Nitrogen $[4,48]$ & 0.796 & 0.534 & & 0.779 & 0.544 & \\
\hline & Time $\times$ Acid $[4,48]$ & 0.654 & 0.627 & & 0.916 & 0.463 & \\
\hline & Time $\times$ Nitrogen $\times$ Acid $[4,48]$ & 3.322 & $0.018^{* *}$ & $\uparrow 203 \%$ & 1.14 & 0.345 & \\
\hline \multirow[t]{7}{*}{ Periphyton } & Nitrogen $[1,12]$ & 2.484 & 0.141 & & 3.040 & 0.106 & \\
\hline & Acid $[1,12]$ & 4.411 & $0.058^{*}$ & $\downarrow 68 \%$ & 0.225 & 0.644 & \\
\hline & Nitrogen $\times$ Acid $[1,12]$ & 2.201 & 0.163 & & 0.821 & 0.383 & \\
\hline & Time $[2,23]$ & 3.708 & $0.078^{*}$ & & 11.137 & $0.006^{* *}$ & \\
\hline & Time $\times$ Nitrogen $[2,23]$ & 1.680 & 0.219 & & 2.927 & 0.113 & \\
\hline & Time $\times$ Acid $[2,23]$ & 2.071 & 0.176 & & 0.205 & 0.658 & \\
\hline & Time $\times$ Nitrogen $\times$ Acid $[2,23]$ & 2.099 & 0.173 & & 4.199 & $0.063^{*}$ & $\uparrow 83 \%$ \\
\hline
\end{tabular}

Note. Numbers in brackets indicate degrees of freedom for RM-ANOVA. Effect size (ES) is calculated for significant treatments by comparing marginal means. ES for significant interaction terms compares the nitrogen + acid treatment to the control. ${ }^{*} p<0.10 ;{ }^{* *} p<0.05$.

likely due to biological uptake (e.g., periphyton) or sedimentation of $\mathrm{N}$, which was not reapplied after the episodic simulation on week 2.

Total phosphorus increased significantly in all tanks during the experiment and was also significantly greater in the acid treatment over time in both the stocked and fishless lake experiments, with 20 and $25 \%$ increases, respectively, compared to control tanks (supporting information S1, Table S2-1, Figure S2-1). A follow-up experiment indicated that the most likely source of the increased phosphorus was a leaching effect from the tanks themselves (supporting information S1, Text S3-1, Figure S3-1). There is no indication that these increases in TP had any noticeable effects on the experimental outcomes. For instance, we would expect an increase in TP to stimulate phytoplankton, particularly in acid treatments, which had the largest increases in TP (supporting information S1, Table S2-1, Figure S2-1). This, however, was not the case, as there were no significant effects of acid on chlorophyll $a$ concentrations (with the exception of one significant interaction), discussed below. Both TN and TP were an order of magnitude higher in the mesocosms and lake samples at the beginning of the experiment (supporting information S1, Figure S2-1, Figure S2-2) compared to historical data (Table 1), likely due to the capture of nutrient run-off following ice-off in July.

Total chlorophyll $a$ concentrations were significantly greater in the nitrogen treatment in the fish-present experiment (Table 2, Figure 2), exhibiting, on average, a 126\% increase following treatment application compared to treatments without nitrogen. There was a significant nitrogen $\times$ acid interaction in the fishpresent experiment, whereby nitrogen had a positive effect on edible chlorophyll $a$ concentration in the presence of acid, exhibiting a threefold increase over controls (Table 2, Figure 2). There were some treatment effects that approached significance in the fishless lake mesocosms, including a $48 \%$ increase in total chlorophyll $a$ in the nitrogen + acid treatment compared to the control and a $46 \%$ decrease in edible chlorophyll $a$ concentration in the nitrogen + acid treatment (Table 2, Figure 2). Although there were no differences between treatments in periphyton growth, there were trends that approached significance: a $68 \%$ decline in the acid treatment in the fish-present experiment and an $83 \%$ increase in the nitrogen + acid treatment, both compared to the control (Table 2, Figure 2). Overall, chlorophyll concentrations in the 

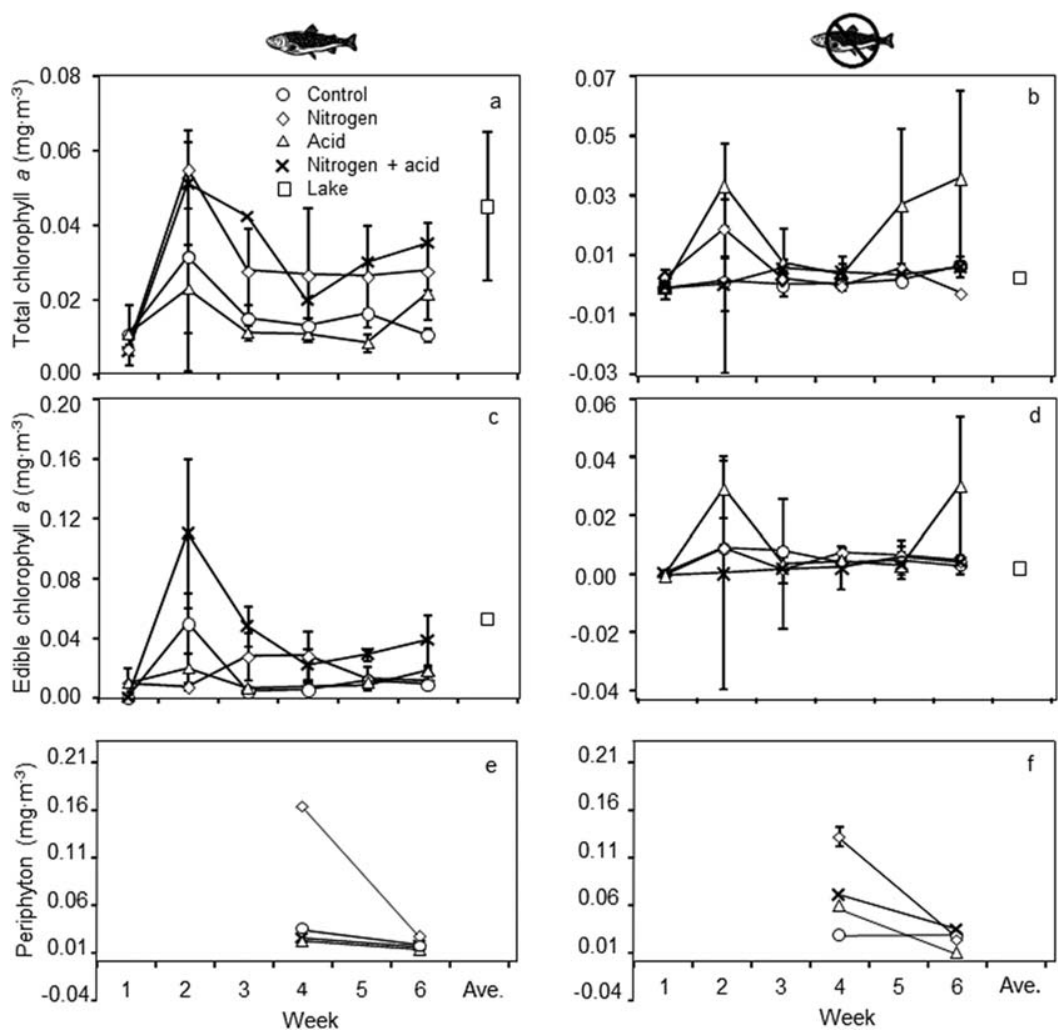

Figure 2. Average chlorophyll a concentration $\left(\mu \mathrm{g} \cdot \mathrm{L}^{-1}\right)$ for both experiments for weeks 1-6 ( $\left.\pm \mathrm{SE}\right)$. (a and b) Total chlorophyll, ( $c$ and d) edible chlorophyll, (e and f) periphyton, in the fish-present community ( $a, c$, and e), and the fishless lake community ( $b, d$, and $f$. The week 2 data point for the nitrogen $\times$ acid treatment in Figure $2 c$ is skewed by two tanks with unusually high values, which gives the appearance of the edible fraction being larger than total. The symbol Lake represents epilimnetic chlorophyll $a$ values from the respective fish-present and fishless lake, averaged over the experiment.

treatment tanks were lower than previously reported and observed in regional lakes, which may have been the result of photoinhibition (Powles, 1984).

\subsection{Zooplankton Community Responses}

Zooplankton abundance in the fish-present experiment increased slightly across all treatments; however there were no significant treatment effects (Table 3, Figures 3a and 4a). Zooplankton biomass spiked on week 2 in the acid treatment, and then declined rapidly on week 3 until the end of the experiment, resulting in a significant difference over time (Table 3, Figures $3 \mathrm{c}$ and $4 \mathrm{c}$ ). There was a significant interaction of nitrogen $\times$ acid in relation to body size in the fish-present experiment, whereby zooplankton were larger in the presence of both nitrogen and acid compared to treatments with just nitrogen or just acid (Table 3, Figures $3 \mathrm{e}$ and $4 \mathrm{e}$ ). The combined effect of stressors was always greater than the predicted additive effect for zooplankton community metrics (Figure 4), suggesting that these stressors have nonadditive effects. In fact, the net effect of the stressors was in the opposite direction (i.e., more positive) than predicted, which is referred to as a reversal or "ecological surprise" (Jackson et al., 2016). Zooplankton abundance and biomass in the treatment tanks was typically greater than values measured in the lake, likely reflecting a release from predation pressure (Figures $3 a$ and $3 c$ ). This may also result from differences in sampling protocols between mesocosms and lakes, where zooplankton could have been missed in lake sampling as a result of diel vertical migration away from predators and/or UV (Williamson et al., 2011).

Zooplankton abundance in the fishless lake experiment generally decreased over time (Figure 3b). There was a significant increase in abundance in the nitrogen treatment, where abundance increased by $31 \%$ over the treatment without nitrogen, likely driven by the peak on week 2 (Table 3, Figure 3b). There was a trend toward an increase in abundance and biomass in the presence of both nitrogen and acid as well in 
Table 3

Statistical Summary of RM-ANOVA on Zooplankton Community Data for Weeks 2-6

\begin{tabular}{|c|c|c|c|c|c|c|c|}
\hline \multirow[b]{2}{*}{ Variable } & \multirow[b]{2}{*}{ Treatment } & \multicolumn{3}{|c|}{ Fish-present experiment } & \multicolumn{3}{|c|}{ Fishless experiment } \\
\hline & & F-ratio & $p$-value & ES & F-ratio & $p$-value & ES \\
\hline \multirow[t]{7}{*}{ Abundance } & Nitrogen $[1,12]$ & 1.327 & 0.272 & & 3.229 & $0.099^{*}$ & $\uparrow 31 \%$ \\
\hline & Acid $[1,12]$ & 0.005 & 0.947 & & $<0.001$ & 0.992 & \\
\hline & Nitrogen $\times$ Acid $[1,12]$ & 0.423 & 0.527 & & 3.216 & $0.098^{*}$ & $\uparrow 27 \%$ \\
\hline & Time $[4,48]$ & 2.750 & $0.039^{* *}$ & & 19.115 & $<0.001^{* * *}$ & \\
\hline & Time $\times$ Nitrogen $[4,48]$ & 1.448 & 0.233 & & 4.875 & $0.002^{* *}$ & $\uparrow 31 \%$ \\
\hline & Time $\times$ Acid $[4,48]$ & 0.687 & 0.604 & & 1.550 & 0.203 & \\
\hline & Time $\times$ Nitrogen $\times$ Acid $[4,48]$ & 0.149 & 0.963 & & 0.450 & 0.772 & \\
\hline \multirow[t]{7}{*}{ Biomass } & Nitrogen $[1,12]$ & 0.349 & 0.566 & & 4.094 & $0.067^{*}$ & $\uparrow 48 \%$ \\
\hline & Acid $[1,12]$ & 1.405 & 0.259 & & 0.667 & 0.430 & \\
\hline & Nitrogen $\times$ Acid $[1,12]$ & 1.785 & 0.206 & & 3.628 & $0.081^{*}$ & $\uparrow 59 \%$ \\
\hline & Time $[4,48]$ & 2.143 & $0.090^{*}$ & & 24.842 & $<0.001$ & \\
\hline & Time $\times$ Nitrogen $[4,48]$ & 1.211 & 0.319 & & 4.769 & $0.003^{* *}$ & $\uparrow 48 \%$ \\
\hline & Time $\times$ Acid $[4,48]$ & 3.228 & $0.020^{* *}$ & $\uparrow 49 \%$ & 3.043 & $0.026^{* *}$ & $\downarrow 23 \%$ \\
\hline & Time $\times$ Nitrogen $\times$ Acid $[4,48]$ & 0.214 & 0.930 & & 1.779 & 0.149 & \\
\hline \multirow[t]{7}{*}{ Body size } & Nitrogen $[1,12]$ & 0.231 & 0.640 & & 2.056 & 0.177 & \\
\hline & Acid $[1,12]$ & 0.122 & 0.733 & & 0.071 & 0.795 & \\
\hline & Nitrogen $\times$ Acid $[1,12]$ & 6.928 & $0.022^{* *}$ & $\uparrow 2 \%$ & 0.085 & 0.775 & \\
\hline & Time $[4,48]$ & 1.821 & 0.140 & & 2.913 & $0.031^{* *}$ & \\
\hline & Time $\times$ Nitrogen $[4,48]$ & 2.019 & 0.107 & & 0.545 & 0.703 & \\
\hline & Time $\times$ Acid $[4,48]$ & 1.434 & 0.237 & & 1.395 & 0.250 & \\
\hline & Time $\times$ Nitrogen $\times$ Acid $[4,48]$ & 0.781 & 0.543 & & 0.660 & 0.623 & \\
\hline
\end{tabular}

Note. Numbers in brackets indicate degrees of freedom for RM-ANOVA. Effect size (ES) is calculated for significant treatments by comparing marginal means. ES for significant interaction terms compares the nitrogen + acid treatment to the control. ${ }^{*} p<0.10 ;{ }^{* *} p<0.05$.

the fishless lake experiment, though it was not significant (Figures $4 \mathrm{~b}$ and $4 \mathrm{~d}$ ). Zooplankton biomass increased significantly over time in the fishless lake experiment nitrogen treatment compared to treatments without nitrogen (48\%) (Table 3, Figures 3d and 4d). There was also significant effect of the acid treatment over time, where biomass decreased $23 \%$ compared to the treatment without acid (Table 3, Figures 3d and 4d). There was no effect of treatments on zooplankton body size in the fishless experiment, though body sizes declined across all treatments over the course of the study (Table 3, Figures $3 f$ and $4 f$ ). As in the fish-present experiment, the combined effect of stressors was always more positive than the predicted additive effect (Figure 4). The mesocosms were similar to ambient lake densities and biomass throughout weeks 3-6 of the experiment (Figure 3b).

Species abundance data revealed that both communities are dominated by a small number of crustacean zooplankton taxa, with most inhabiting both lakes (Figure 5). Given these similarities in composition, their abundances within each community varied markedly and responded differently to treatment applications. A PERMANOVA was used to test if the treatments had an effect on community composition, and revealed a nearly significant trend with the acid treatment in the fishless community experiment $\left(F_{1,12}=2.638\right.$, $p=0.063$ ). We observed a decline in the calanoid, Hesperodiaptomus franciscanus, which dominated the composition in the first 2 weeks, and increases in the cladocerans Daphnia rosea and Holopedium gibberum through week 6 (Figure 5f). By contrast, the controls in the fishless experiment maintained consistent population sizes of $H$. gibberum and slower growth of D. pulicaria (Figure $5 b$ ).

\section{Discussion}

Nitrogen deposition can lead to acidification and eutrophication in high elevation lakes, many of which have been subjected to the introduction of top predator fishes. This combination of stressors may be particularly stressful for communities characterized by a few specialized species. Data from mesocosms at the beginning of the experiment indicate that zooplankton body size and biomass were greater in the fishless experiment compared to the fish-present experiment, supporting our hypothesis that fish predation is affecting zooplankton communities in these mountain lakes (Brooks \& Dodson, 1965; Eby et al., 2006). We 

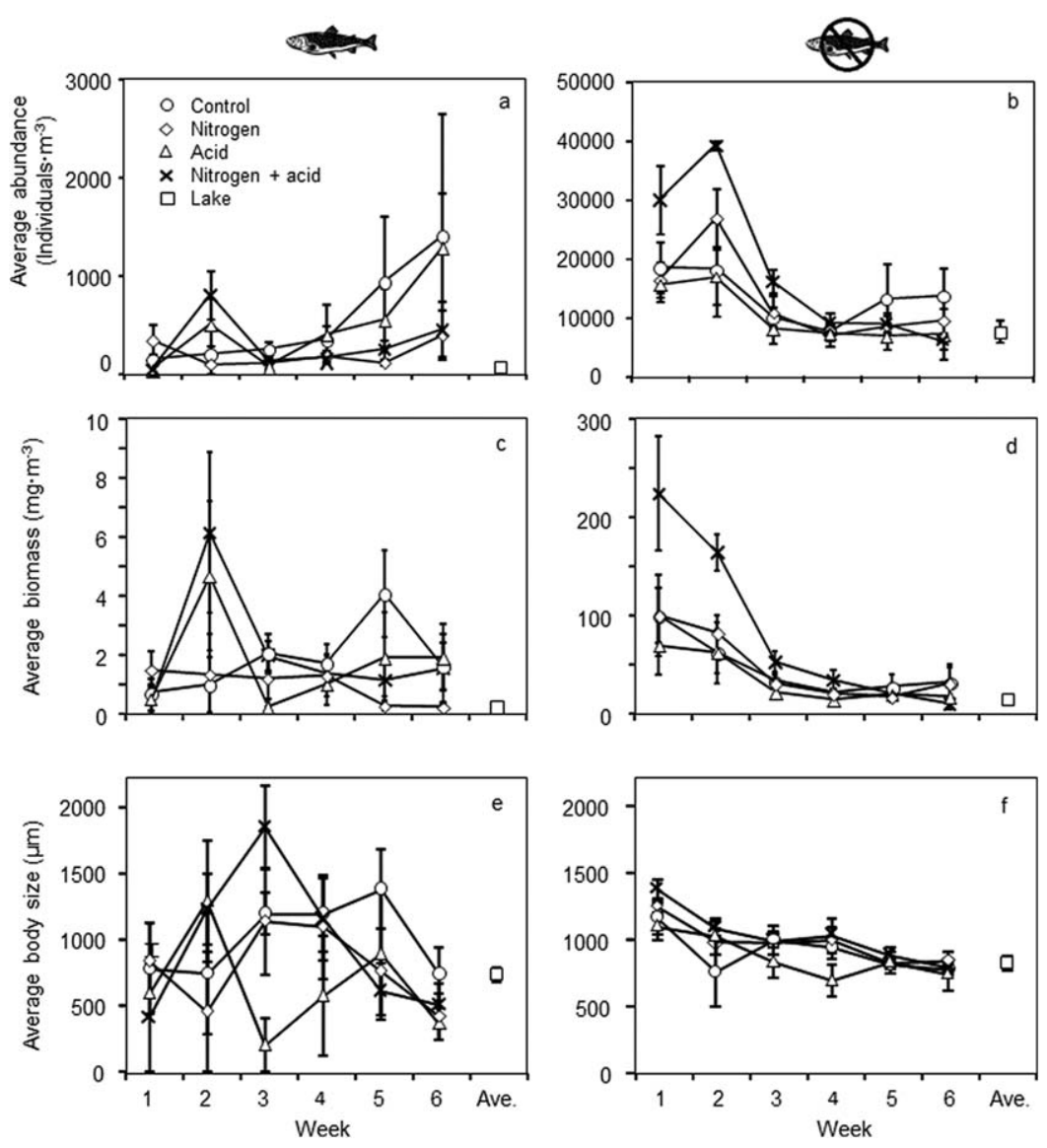

Figure 3. Average (a and b) zooplankton abundance (individuals $\left.\cdot \mathrm{m}^{-3}\right)$, (c and d) biomass $\left(\mathrm{mg} \cdot \mathrm{m}^{-3}\right.$ ), and (e and f) body size $(\mu \mathrm{m})$ for weeks 1-6 for both experiments $( \pm \mathrm{SE})$. Note differences in $y$ axis scales between fish-present and fishless lake experiments. The symbol Lake represents zooplankton water column values from the respective fish-present and fishless lake, averaged over the experiment.

found that treatments simulating the effects of acidification and eutrophication sometimes had the opposite effect on chlorophyll concentrations and zooplankton communities from fishless versus fish-present communities. Additionally, we found that there were largely weak effects when acidification and eutrophication treatments were combined, frequently leading to reversals, where the combined effects were in the opposite direction of the predicted additive effect of individual stressors. These results suggest that nitrogen deposition may present complex challenges for managers attempting to protect and restore lakes following fish introductions.

Acidification in freshwater systems has been shown to cause a variety of impacts to zooplankton, and those communities with low species richness may have limited abilities to adapt to increased acidity, potentially leading to a loss of ecosystem function (Yachi \& Loreau, 1999). We predicted that both zooplankton communities would respond negatively to the acid treatment as a result of declines in the dominant acidsensitive taxa such as Daphnia pulicaria, Daphnia rosea, and Hesperodiaptomus franciscanus (Havas \& Hutchinson, 1982; Walton et al., 1982). Although there was a significant decline in zooplankton biomass in the acid treatment over the course of the fishless lake experiment, the biomass of the fish-present experiment increased over time (Figure 3). The acid treatment was dominated by small-bodied acid-tolerant crustaceans such as Scapholeberis and Chydorus sphaericus at the end of the fish-present experiment (Figure 5), in agreement with our hypothesis. However, these small-bodied taxa were largely absent from the fishless experiment, suggesting that zooplankton in fishless lakes may be more sensitive to the effects of acidification compared to lakes with fish. This result must be tempered by the nature of our experiment: in a natural lake setting with fish present, it is possible that predation would limit this response to acidification. However, Scapholeberis and C. sphaericus are littoral taxa (Walseng et al., 2003) and would likely be able to 

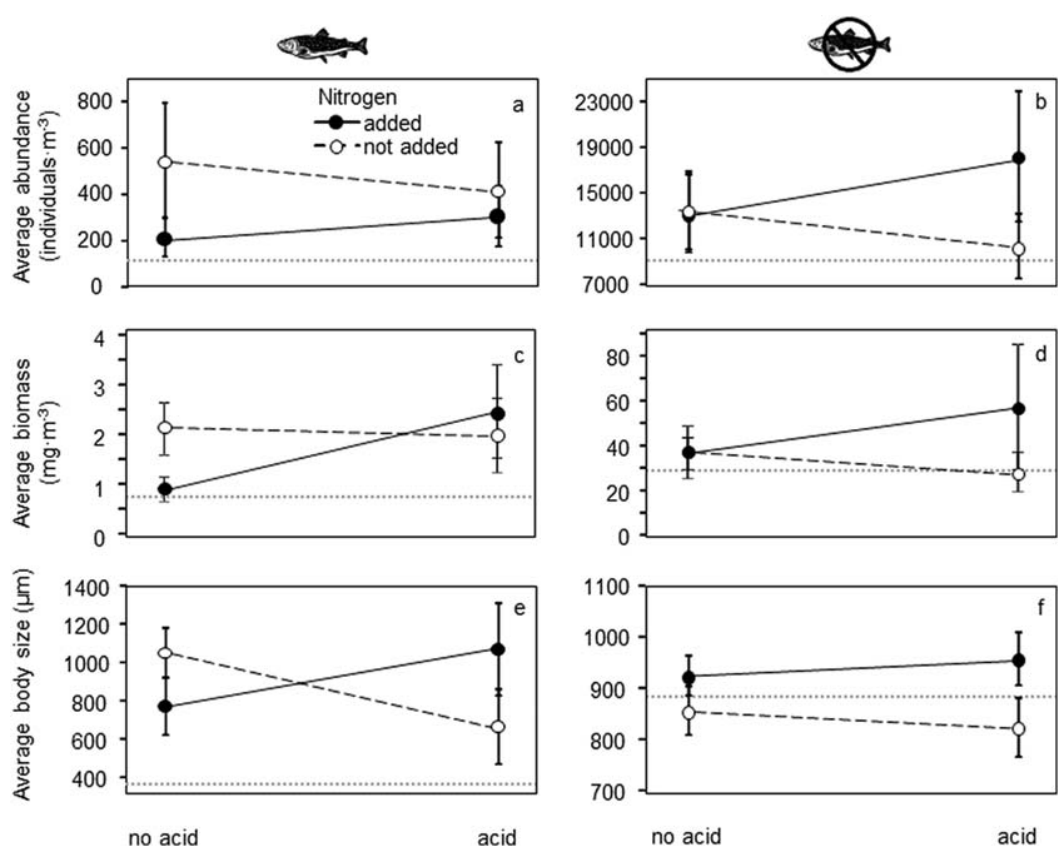

Figure 4. Interaction plots for average (a and b) zooplankton abundance (individuals $\left.\cdot \mathrm{m}^{-3}\right)$, (c and d) biomass $\left(\mathrm{mg} \cdot \mathrm{m}^{-3}\right)$, and (e and $f$ ) body size $(\mu \mathrm{m})$ for weeks $2-6$ for both experiments ( \pm SE). Dashed gray line indicates the predicted additive effect of the nitrogen + acid treatment.

escape predation, suggesting that this result may persist in natural systems. Interestingly, $H$. franciscanus seemed to initially tolerate acid relatively well, dominating the community in the acid treatment in the first 2 weeks of the both experiments (Figure 5). However, this trend did not persist, with declines observed for the last 4 weeks of both experiments. Thus, the response of some zooplankton species and overall communities may be context-dependent, necessitating careful study of community responses to stressors.

The addition of limiting nutrients (nitrogen and phosphorus) has been shown to increase primary productivity and augment food availability for primary consumers (Elser et al., 2007). As predicted, the zooplankton community in the fishless lake experiment increased in abundance and biomass in response to the nitrogen treatment, driven by an early peak in abundance of $H$. gibberum and $H$. franciscanus (Figure 3). Daphnia pulicaria remained low in the fishless lake experiment until week 4 in all treatments, which is surprising considering that in other systems, Daphnia outcompete H. gibberum for food (Allan, 1973; Tessier, 1986). Given the equal additions of nitrogen in both the fishless and fish-present experiments, total chlorophyll $a$ concentrations would have been expected to be more similar, yet concentrations were notably lower in the fishless lake experiment (average chlorophyll $a$ with nitrogen addition: fishless $=0.007 \mathrm{mg} \cdot \mathrm{m}^{-3} \pm 0.009 \mathrm{SD}$; fishpresent $=0.031 \mathrm{mg} \cdot \mathrm{m}^{-3} \pm 0.012 \mathrm{SD}$; Figure 2). The differences in chlorophyll concentrations between experiments could indicate that an early peak in available phytoplankton was consumed more aggressively by the herbivorous taxa in the fishless experiment in the first few days following nutrient addition. Thus, the lower abundance of zooplankton in the fish-present experiment may have resulted in less grazing and higher chlorophyll a concentrations.

Acidification and eutrophication can negatively affect aquatic biota; however this study sought to explore the interactions that could result from both stressors occurring at the same time. Previous work has observed declines in zooplankton biomass from fish-present lakes as a result of nitrogen and acid addition causing phytoplankton to become less palatable (Lafrancois et al., 2004). In our study, zooplankton abundance and biomass from the fish-present experiment were not affected by the combined treatment of acid and nitrogen, though average body size was affected (Figure 4). This interaction reflects the shift to smaller zooplankton taxa in the acid and nitrogen treatments, compared to larger taxa in the combined treatment of acid and nitrogen. The differences in our results from those of Lafrancois et al. (2004) could be due to our more subtle treatment additions, which failed to induce direct mortality. There were also no significant interactions between acid and nitrogen in the fishless lake experiment; however there were some moderate 

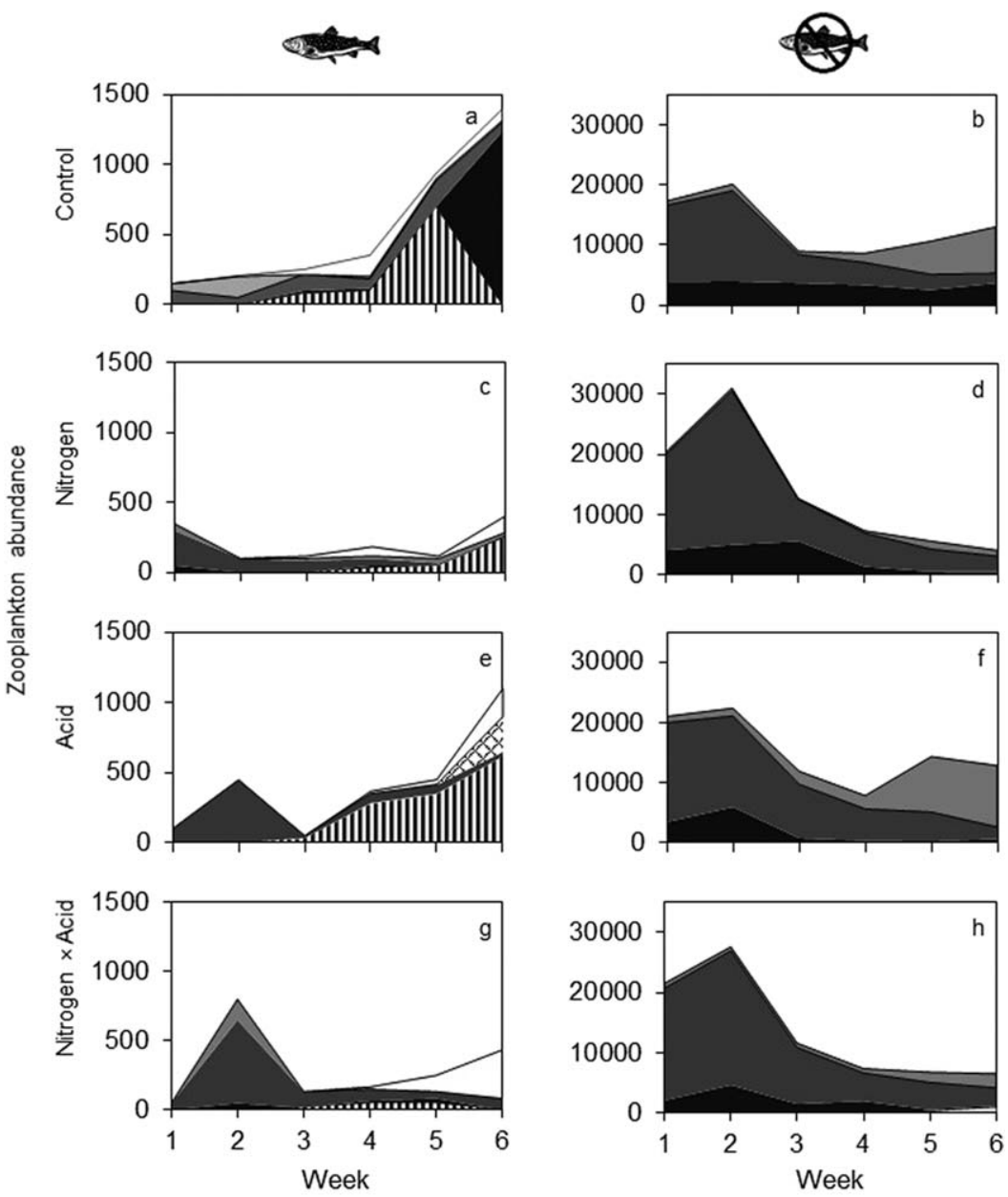

III Scapholeberis sp.
Daphnia spp.

H. gibberum

H. franciscanus

因 C. sphaericus

E. agilis

Figure 5. Species abundance (individuals $\cdot \mathrm{m}^{-3}$ ) for weeks $1-6$ for both experiments, averaged by treatment: $(a$ and $b$ ) control, (c and d) nitrogen, (e and f) acid, $(g$ and h) nitrogen + acid in the stocked lake experiment $(a, c, e, a n d g)$ and the fishless lake experiment (b, $d, f$, and $h)$.

trends of increased abundance and biomass with the addition of both nitrogen and acid (Figure 4). These interactions could be a result of the increase in some species before the acid treatment could cause chronic or delayed impacts (Figure 5). Delayed impacts of moderate pH on Daphnia rosea was also observed in the experimental acidification of a high elevation lake in the Sierra Nevada (Barmuta et al., 1990). Another possible explanation is that some taxa were released from competition as a result of loss of acid-sensitive taxa from the community, allowing other taxa to reproduce and grow, taking advantage of the higher nitrogen availability. The overall trend toward an increase or no change in abundance and biomass of the fishless and fish-present experiments, respectively, compared to controls was unexpected: instead of compounding negative individual effects of both variables, their sum was less harmful than predicted, resulting in reversals or ecological surprises (Jackson et al., 2016). It is noteworthy that reversals were the least common outcome of freshwater multiple stressor studies in the meta-analysis of Jackson et al. (2016). Our results support the hypothesis that reversals can occur when one of the stressors can act as a stimulant, such as nutrients (Boone \& Bridges-Britton, 2006) or warmer temperatures (Jackson et al., 2016).

Our interpretations are based on the hypothesis that fish presence or absence had a significant role in structuring zooplankton communities in our study systems. As described in the Methods, the study lakes were chosen to be as similar as possible in terms of water chemistry, morphometry, temperature, and 
productivity (Table 1). Although there were slight differences in productivity and temperature between fishless and fish-present lakes, if these factors were significant than we would have observed different patterns in the zooplankton communities (i.e., greater abundance, biomass, and body size in the fish-present lake). Alternately, if fish were not responsible for differences in initial community structure, another interpretation of our results is that the response of zooplankton communities to multiple stressors is dependent upon initial community composition. For instance, the acid treatment had an unexpected positive effect on zooplankton biomass in the fish-present lake, which we attribute to the presence of small-bodied acid-tolerant taxa, such as Scapholeberis and Chydorus sphaericus, which were either absent or in very low numbers in lake samples at the beginning of the experiment, respectively (supporting information S1, Figure S1-1). Thus, species traits may be a useful indicator of the potential response to multiple anthropogenic stressors.

In order to observe the most realistic responses, these experiments would have been conducted in the waterbodies themselves; however, due to park regulations, mesocosm tanks were used to recreate similar conditions (e.g., Strecker et al., 2004; Vakkilainen et al., 2004) posing little threat to the sensitive montane ecosystems. Small-scale experiments have been criticized for misrepresenting lake dynamics and attempting to extrapolate to the ecosystem level (Schindler, 1998). For instance, alterations to organisms that result from a mesocosm experiment (e.g., stress from collection and transportation, withdrawal, or addition of predators) can lead to bottle effects that could also be responsible for changes in response variables, in addition to the prescribed treatments. Additionally, our experiment lacked the trophic (e.g., fish, macroinvertebrates) and physical complexity of a lake environment. For example, high light levels encountered in our shallow mesocosms in a montane region may have reduced photosynthesis in algal cells via photoinhibition (Powles, 1984). However, the zooplankton and chlorophyll data reveal that values observed in the tanks were often within the range observed in the lakes (Figure 4), suggesting that our study was a realistic simulation. It is likely that the simplistic design used in this experiment did not account for the more complex pathways through which acidification and eutrophication occur in a natural setting, and the mediating effect of soils and vegetation in the watershed. Despite these drawbacks, this design is the most feasible way to decipher differences between zooplankton community responses to simulations of multiple stressors. Therefore, these experiments provide managers the most tangible estimates for how aquatic communities could respond to future changes, and assess the mechanisms that lead to changes in composition without whole-lake manipulations.

\section{Conclusion}

In low productivity systems, such as ultraoligotrophic montane lakes, additions of nitrogen could increase zooplankton abundance and biomass, offsetting the negative effects of acidification, and lead to an ecological surprise. However, the results from our experiment indicate that the addition of acid and nitrogen to a system may have differential impacts on zooplankton based on fish stocking history, and that not all stressors have negative effects. The removal of nonnative trout species is a current strategy for restoring native invertebrate populations in montane lakes. For example, the U.S. Forest Service has been restoring lakes to a fishless state since 2008 in the Lake Tahoe Basin Management Unit (Muskopf et al., 2011), while the National Park Service has been following an adaptive management plan that actively removes fish from lakes in most parks since 2009 (National Park Service, 2008). Little is known about how these systems will recover once returned to a fishless state and whether they will be more or less at risk to future perturbations. Future work should examine how other stressors, such as contaminants and novel invasive species, may affect mountain lake communities and whether ecological surprises or reversals are a widespread phenomenon in mountain ecosystems.

\section{References}

Allan, J. D. (1973). Competition and the relative abundances of two cladocerans. Ecology, 54(3), 484-498. https://doi.org/10.2307/1935334 Anderson, D. M., Glibert, P. M., \& Burkholder, J. M. (2002). Harmful algal blooms and eutrophication: Nutrient sources, composition, and consequences. Estuaries, 25(4), 704-726. https://doi.org/10.1007/BF02804901

Anderson, M. J. (2001). A new method for non-parametric multivariate analysis of variance. Austral Ecology, 26(1), 32-46. https://doi.org/10. 1111/j.1442-9993.2001.01070.pp.x

Arar, E. J., \& Collins, G. B. (1997). In vitro determination of chlorophyll a and pheophytin a in marine and freshwater algae by fluorescence, Method 445 (Procedural Report). Washington, DC: U.S. Environmental Protection Agency, National Exposure Research Laboratory. 
Armstrong, F. A. J., \& Schindler, D. W. (1971). Preliminary chemical characterization of waters in the experimental lakes area, northwestern Ontario. Journal of the Fisheries Research Board of Canada, 28(2), 171-187. https://doi.org/10.1139/f71-030

Bahls, P. (1992). The status of fish populations and management of high mountain lakes in the western United States. Northwest Science, 66(3), 183-193.

Barmuta, L. A., Cooper, S. D., Hamilton, S. K., Kratz, K. W., \& Melack, J. M. (1990). Responses of zooplankton and zoobenthos to experimental acidification in a high-elevation lake (Sierra Nevada, California, U.S.A.). Freshwater Biology, 23(3), 571-586. https://doi.org/10.1111/j. 1365-2427.1990.tb00296.x

Baron, J. S., Driscoll, C. T., Stoddard, J. L., \& Richer, E. E. (2011). Empirical critical loads of atmospheric nitrogen deposition for nutrient enrichment and acidification of sensitive US lakes. BioScience, 61(8), 602-613. https://doi.org/10.1525/bio.2011.61.8.6

Baron, J. S., Rueth, H. M., Wolfe, A. M., Nydick, K. R., Allstott, E. J., Minear, J. T., \& Moraska, B. (2000). Ecosystem responses to nitrogen deposition in the Colorado Front Range. Ecosystems, 3(4), 352-368. https://doi.org/10.1007/s100210000032

Battarbee, R. W., Grytnes, J.-A., Thompson, R., Appleby, P. G., Catalan, J., Korhola, A., et al. (2002). Comparing palaeolimnological and instrumental evidence of climate change for remote mountain lakes over the last 200 years. Journal of Paleolimnology, 28, $161-179$.

Battarbee, R. W., Kernan, M., \& Rose, N. (2009). Threatened and stressed mountain lakes of Europe: Assessment and progress. Aquatic Ecosystem Health \& Management, 12, 118-128. https://doi.org/10.1080/14634980902905742

Boone, M. D., \& Bridges-Britton, C. M. (2006). Examining multiple sublethal contaminants on the gray treefrog (Hyla versicolor): Effects of an insecticide, herbicide, and fertilizer. Environmental Toxicology and Chemistry, 25, 3261-3265. https://doi.org/10.1897/06-235R.1

Brakke, D. F., \& Loranger, T. J. (1987). Acid neutralizing capacity of lakes in the North Cascades area of Washington State. In H. C. Martin (Ed.), Acidic Precipitation (pp. 1045-1053). Dordrecht, the Netherlands: Springer.

Brooks, J. L., \& Dodson, S. I. (1965). Predation, body size, and composition of plankton. Science, 150(3692), 28-35. https://doi.org/10.1126/ science.150.3692.28

Carlisle, D. M., \& Hawkins, C. P. (1998). Relationships between invertebrate assemblage structure, 2 trout species, and habitat structure in Utah mountain lakes. Journal of North American Benthological Society, 17, 286-300. https://doi.org/10.2307/1468332

Clow, D. W., \& Campbell, D. H. (2008). Atmospheric deposition and surface-water chemistry in Mount Rainier and North Cascades National Parks, U.S.A., water years 2000 and 2005-2006 (U.S. Geol. Surv. Sci. Invest. Rep. 2008-5152, 37 p.). Reston, Virginia: U.S. Geological Survey.

Clow, D. W., Striegl, R. G., Nanus, L., Mast, M. A., Campbell, D. H., \& Krabbenhoft, D. P. (2002). Chemistry of selected high-elevation lakes in seven national parks in the western United States. Water, Air, and Soil Pollution: Focus, 2(2), 139-164. https://doi.org/10.1023/ A:1020102608378

Confer, J. L., Kaaret, T., \& Likens, G. E. (1983). Zooplankton diversity and biomass in recently acidified lakes. Canadian Journal of Fisheries and Aquatic Sciences, 40(1), 36-42. https://doi.org/10.1139/f83-006

Cooperative Chemical Analytical Laboratory. (2010). Standard operating procedure for the digestion and analysis of fresh water samples for total phosphorus and total dissolved phosphorus, Method 41A.1 (Procedural Report). Corvallis, Oregon: College of Forestry, Oregon State University.

Cooperative Chemical Analytical Laboratory. (2013). Standard operating procedure for the digestion and analysis of fresh water samples for total nitrogen and total dissolved nitrogen, Method 33A.3 (Procedural Report). Corvallis, Oregon: College of Forestry, Oregon State University.

Culver, D. A., Boucherle, M. M., Bean, D. J., \& Fletcher, J. W. (1985). Biomass of freshwater crustacean zooplankton from length-weight regressions. Canadian Journal of Fisheries and Aquatic Sciences, 42(8), 1380-1390. https://doi.org/10.1139/f85-173

Cyr, H., \& Curtis, J. M. (1999). Zooplankton community size structure and taxonomic composition affects size-selective grazing in natural communities. Oecologia, 118(3), 306-315. https://doi.org/10.1007/s004420050731

Donald, D. B., Vinebrooke, R. D., Anderson, R. S., Syrgiannis, J., \& Graham, M. D. (2001). Recovery of zooplankton assemblages in mountain lakes from the effects of introduced sport fish. Canadian Journal of Fisheries and Aquatic Sciences, 58(9), 1822-1830. https://doi.org/10. 1139/f01-121

Eby, L. A., Roach, W. J., Crowder, L. B., \& Stanford, J. A. (2006). Effects of stocking-up freshwater food webs. Trends in Ecology \& Evolution, 21(10), 576-584. https://doi.org/10.1016/j.tree.2006.06.016

Elser, J. J., Bracken, M. E. S., Cleland, E. E., Gruner, D. S., Harpole, W. S., Hillebrand, H., et al. (2007). Global analysis of nitrogen and phosphorus limitation of primary producers in freshwater, marine and terrestrial ecosystems. Ecology Letters, 10(12), 1135-1142. https://doi.org/ 10.1111/j.1461-0248.2007.01113.x

Elser, J. J., Kyle, M., Steger, L., Nydick, K. R., \& Baron, J. S. (2009). Nutrient availability and phytoplankton nutrient limitation across a gradient of atmospheric nitrogen deposition. Ecology, 90(11), 3062-3073. https://doi.org/10.1890/08-1742.1

Environmental Protection Agency. (2003). Standard operating procedure for zooplankton analysis (Procedural Report). Chicago, Illinois: Environmental Protection Agency, Great Lakes National Program Office.

Fenn, M. E., Baron, J. S., Allen, E. B., Rueth, H. M., Nydick, K. R., Geiser, L., et al. (2003). Ecological effects of nitrogen deposition in the western United States. BioScience, 53(4), 404-420. https://doi.org/10.1641/0006-3568(2003)053[0404:EEONDI]2.0.CO;2

Folt, C. L., Chen, C. Y., Moore, M. V., \& Burnaford, J. (1999). Synergism and antagonism among multiple stressors. Limnology and Oceanography, 44(3), 864-877. https://doi.org/10.4319/lo.1999.44.3_part_2.0864

Galloway, J. N., Aber, J. D., Erisman, J. W., Seitzinger, S. P., Howarth, R. W., \& Cowling, E. B. (2003). The nitrogen cascade. BioScience, 53(4), 341-356. https://doi.org/10.1641/0006-3568(2003)053\%5B0341:TNC\%5D2.0.CO;2

Hall, D. J., Threlkeld, S. T., Burns, C. W., \& Crowley, P. H. (1976). The size-efficiency hypothesis and the size structure of zooplankton communities. Annual Review of Ecology and Systematics, 7, 177-208. https://doi.org/10.2307/2096865

Hambright, K. D., \& Hall, R. O. (1992). Differential zooplankton feeding behaviors, selectivities, and community impacts of 2 planktivorous fishes. Environmental Biology of Fishes, 35, 401-411. https://doi.org/10.1007/BF00004992

Haney, J. F. (2013). An image based key to the zooplankton of North America. Identification Key. Durham, NH: University of New Hampshire, Center for Freshwater Biology. Retrieved from http://cfb.unh.edu/cfbkey/html/

Havas, M., \& Hutchinson, T. C. (1982). Aquatic invertebrates from the Smoking Hills, N.W.T.: Effect of pH and metals on mortality. Canadian Journal of Fisheries and Aquatic Sciences, 39(6), 890-903. https://doi.org/10.1139/f82-120

Havens, K. E., Yan, N. D., \& Keller, W. (1993). Lake acidification: Effects on crustacean zooplankton populations. Environmental Science \& Technology, 27(8), 1621-1624. https://doi.org/10.1021/es00045a019

Jackson, M. C., Loewen, C. J. G., Vinebrooke, R. D., \& Chimimba, C. T. (2016). Net effects of multiple stressors in freshwater ecosystems: A meta-analysis. Global Change Biology, 22, 180-189. https://doi.org/10.1111/gcb.13028

Keller, W., \& Yan, N. D. (1998). Biological recovery from lake acidification: Zooplankton communities as a model of patterns and processes. Restoration Ecology, 6(4), 364-375. https://doi.org/10.1046/j.1526-100X.1998.06407.x 
Knapp, R. A., Matthews, K. R., \& Sarnelle, O. (2001). Resistance and resilience of alpine lake fauna to fish introductions. Ecological Monographs, 71(3), 401-421. https://doi.org/10.1890/0012-9615(2001)071[0401:RAROAL]2.0.CO;2

Lafrancois, B. M., Nydick, K. R., Johnson, B. M., \& Baron, J. S. (2004). Cumulative effects of nutrients and pH on the plankton of two mountain lakes. Canadian Journal of Fisheries and Aquatic Sciences, 61(7), 1153-1165. https://doi.org/10.1139/F04-053

Lawrence, M. A. (2013). ez: Easy analysis and visualization of factorial experiments. Retrieved from http://github.com/mike-lawrence/ez

Lawrence, S. G., Malley, D. F., Findlay, W. J., Maclver, M. A., \& Delbaere, I. L. (1987). Method for estimating dry weight of freshwater planktonic crustaceans from measures of length and shape. Canadian Journal of Fisheries and Aquatic Sciences, 44(S1), s264-s274.

Legendre, P., \& Gallagher, E. D. (2001). Ecologically meaningful transformations for ordination of species data. Oecologia, 129, $271-280$. https://doi.org/10.1007/s004420100716

Liss, W. J., Larson, G. L., \& Hoffman, R. L. (2002). Ecological impact of introduced trout on native aquatic communities in mountain lakes: Phase III final report (Pacific Northwest Region technical report, 102 p.). Corvallis, OR: U.S. Geological Survey.

McCauley, E. (1984). The estimation of the abundance and biomass of zooplankton in samples. In J. A. Downing, \& F. H. Rigler (Eds.), A manual on the methods for the assessment of secondary productivity in freshwaters (pp. 228-265). Oxford, UK: Blackwell Scientific Publications.

McCullough, C. D., \& Horwitz, P. (2010). Vulnerability of organic acid tolerant wetland biota to the effects of inorganic acidification. Science of the Total Environment, 408(8), 1868-1877. https://doi.org/10.1016/j.scitotenv.2010.01.034

McQueen, D. J., Post, J. R., \& Mills, E. L. (1986). Trophic relationships in freshwater pelagic ecosystems. Canadian Journal of Fisheries and Aquatic Sciences, 43(8), 1571-1581. https://doi.org/10.1139/f86-195

Messner, J. S., MacLennan, N. M., \& Vinebrooke, R. D. (2013). Higher temperatures enhance the effects of invasive sportfish on mountain zooplankton communities. Freshwater Biology, 58, 354-364. https://doi.org/10.111/fwb.12062

Muskopf, S., Santora, M., Bindl, M., \& Lemmers, C. (2011). Sierra Nevada Yellow-Legged frog habitat restoration project in the Desolation Wilderness annual report (Annual Report). South Lake Tahoe, CA: U.S.D.A Forest Service.

Nanus, L., \& Clow, D. W. (2004). Sensitivity of lakes in wilderness areas in Oregon and Washington to atmospheric deposition (Administrative Report). South Lake Tahoe, CA: U.S.D.A Forest Service.

Nanus, L., Clow, D. W., Saros, J. E., Stephens, V. C., \& Campbell, D. H. (2012). Mapping critical loads of nitrogen deposition for aquatic ecosystems in the Rocky Mountains, USA. Environmental Pollution, 166, 125-135. https://doi.org/10.1016/j.envpol.2012.03.019

National Park Service. (2008). North Cascades National Park Service Complex mountain lakes fishery management plan. Washington, DC: Environmental Impact Statement, Department of the Interior.

Neill, W. E. (1984). Regulation of rotifer densities by crustacean zooplankton in an oligotrophic montane lake in British Columbia. Oecologia, 61, 175-181. https://doi.org/10.1007/BF00396756

Odum, E. P., Finn, J. T., \& Franz, E. H. (1979). Perturbation theory and the subsidy-stress gradient. BioScience, 29(6), 349-352. https://doi.org/ $10.2307 / 1307690$

Pilliod, D. S., \& Peterson, C. R. (2001). Local and landscape effects of introduced trout on amphibians in historically fishless watersheds. Ecosystems, 4(4), 322-333. https://doi.org/10.1007/s10021-001-0014-3

Pister, E. P. (2001). Wilderness fish stocking: History and perspective. Ecosystems, 4, 279-286. https://doi.org/10.1007/s10021-001-0010-7

Powles, S. B. (1984). Photoinhibition of photosynthesis induced by visible light. Annual Review of Plant Physiology, 35, 15-44. https://doi. org/10.1146/annurev.pp.35.060184.000311

R Core Team (2013). R: A language and environment for statistical computing. Vienna, Austria: R Foundation for Statistical Computing Retrieved from http://www.R-project.org

Sarnelle, O., \& Knapp, R. A. (2005). Nutrient recycling by fish versus zooplankton grazing as drivers of the trophic cascade in alpine lakes. Limnology and Oceanography, 50(6), 2032-2042. https://doi.org/10.4319/lo.2005.50.6.2032

Schilling, E. G., Loftin, C. S., \& Huryn, A. D. (2009). Effects of introduced fish on macroinvertebrate communities in historically fishless headwater and kettle lakes. Biological Conservation, 142(12), 3030-3038. https://doi.org/10.1016/j.biocon.2009.08.003

Schindler, D. W. (1990). Experimental perturbations of whole lakes as tests of hypotheses concerning ecosystem structure and function. Oikos, 57(1), 25-41. https://doi.org/10.2307/3565733

Schindler, D. W. (1998). Whole-ecosystem experiments: Replication versus realism: The need for ecosystem-scale experiments. Ecosystems, 1(4), 323-334. https://doi.org/10.1007/s100219900026

Schindler, D. W., Curtis, P. J., Parker, B. R., \& Stainton, M. P. (1996). Consequences of climate warming and lake acidification for UV-B penetration in North American boreal lakes. Nature, 379(6567), 705-708. https://doi.org/10.1038/379705a0

Schindler, D. W., \& Parker, B. R. (2002). Biological pollutants: Alien fishes in mountain lakes. Water Air and Soil Pollution: Focus, $2,379-397$.

Strecker, A. L., Cobb, T. P., \& Vinebrooke, R. D. (2004). Effects of experimental greenhouse warming on phytoplankton and zooplankton communities in fishless alpine ponds. Limnology and Oceanography, 49(4), 1182-1190.

Strecker, A. L., Milne, R., \& Arnott, S. E. (2008). Dispersal limitation and climate-related environmental gradients structure microcrustacean composition in freshwater lakes, Ellesmere Island, Canada. Canadian Journal of Fisheries and Aquatic Sciences, 65, 1905-1918. https://doi. org/10.1139/F08-097

Tessier, A. J. (1986). Comparative population regulation of two planktonic cladocera (Holopedium gibberum and Daphnia catawba). Ecology, 67(2), 286-302. https://doi.org/10.2307/1938573

Thorp, J. H., \& Covich, A. P. (2009). Ecology and classification of North American freshwater invertebrates (3rd ed.). Boston, MA: Academic Press.

Tremblay, S., \& Magnan, P. (1991). Interactions between 2 distantly related species, brook trout (Salvelinus fontinalis) and white sucker (Catostomus commersoni). Canadian Journal of Fisheries and Aquatic Sciences, 48, 857-867. https://doi.org/10.1139/f91-102

Vakkilainen, K., Kairesalo, T., Hietala, J., Balayla, D. M., Bécares, E., Van de Bund, W. J., et al. (2004). Response of zooplankton to nutrient enrichment and fish in shallow lakes: A pan-European mesocosm experiment. Freshwater Biology, 49(12), 1619-1632. https://doi.org/10. $1111 / j .1365-2427.2004 .01300 . x$

Vander Zanden, M. J., Casselman, J. M., \& Rasmussen, J. B. (1999). Stable isotope evidence for the food web consequences of species invasions in lakes. Nature, 401(6752), 464-467. https://doi.org/10.1038/46762[Mismatch]

Walseng, B., Yan, N. D., \& Schartau, A. K. (2003). Littoral microcrustacean (Cladocera and Copepoda) indicators of acidification in Canadian Shield lakes. Ambio, 32, 208-213. https://doi.org/10.1579/0044-7447-32.3.208

Walton, W. E., Compton, S. M., Allan, J. D., \& Daniels, R. E. (1982). The effect of acid stress on survivorship and reproduction of Daphnia pulex (Crustacea: Cladocera). Canadian Journal of Zoology, 60(4), 573-579. https://doi.org/10.1139/z82-085

Williams, J. J., Beutel, M., Nurse, A., Moore, B., Hampton, S. E., \& Saros, J. E. (2016). Phytoplankton responses to nitrogen enrichment in Pacific Northwest, USA Mountain Lakes. Hydrobiologia, 776, 261-276. https://doi.org/10.1007/s10750-016-2758-y 
Williamson, C. E., Dodds, W., Kratz, T. K., \& Palmer, M. A. (2008). Lakes and streams as sentinels of environmental change in terrestrial and atmospheric processes. Frontiers in Ecology and the Environment, 6(5), 247-254. https://doi.org/10.1890/070140

Williamson, C. E., Fischer, J. M., Bollens, S. M., Overholt, E. P., \& Breckenridge, J. K. (2011). Toward a more comprehensive theory of zooplankton diel vertical migration: Integrating ultraviolet radiation and water transparency into the biotic paradigm. Limnology and Oceanography, 56, 1603-1623. https://doi.org/10.4319/lo.2011.56.5.1603

Yachi, S., \& Loreau, M. (1999). Biodiversity and ecosystem productivity in a fluctuating environment: The insurance hypothesis. Proceedings of the National Academy of Sciences of the United States of America, 96(4), 1463-1468. https://doi.org/10.1073/pnas.96.4.1463 